\title{
Neural Plasticity: Influencing Elements and Modulation Techniques
}

\section{Kun Li and Maxwell Boakye*}

Department of Neurosurgery, University of Louisville, Louisville, Kentucky, United States

\begin{abstract}
It is believed that neural plasticity plays an important role in the process of human cognition and motor practicing. Tremendous researches on neural plasticity have been done in the past 30 years. In this paper, we discussed the factors that may affect neural plasticity and the widely used modulation techniques. The purpose of this review is to present the current-state-of-art of neural plasticity studies and help readers to envision the future research directions.
\end{abstract}

Keywords: Neural plasticity; Motor training; d-amphetamine; Sensory input; Repetitive transcranial magnetic stimulation; Transcranial direct current stimulation; Brain-derived neurotrophic factor

\section{Introduction}

Neural plasticity, also known as brain plasticity, cortical plasticity and other terms, refers to the structural and functional reorganization ability of brain and nervous system as a result of input from the environment. It was formerly thought to exist only in early postnatal periods [1]. However, recent researches have shown enough evidences of modulating the neural plasticity in adult human subjects. A classic well-known experiment of modulating neural plasticity in adult human subject was performed by Classen et al. [2]. In their research, transcranial magnetic stimulation (TMS) is applied over the subjects' motor cortex to elicit directional thumb movement. After the preferred direction of thumb movement is established, subjects are asked to repetitively move their thumb to the opposite direction for a period of 30 minutes. Once the motor training is done, TMS is applied to the same area of the motor cortex again. At this point, it is observed that the direction of subjects' thumb movement elicited by TMS change to the trained direction which is opposite to the original thumb movement direction. This experiment shows that active motor training induces rapid change in cortical representation of the thumb. Therefore it is considered as a supportive evidence of the assumption that neural plasticity of adult human subject can be modulated by appropriately designed motor task. Neural plasticity is believed to play an important role in the process of motor learning, skill acquisition [3] and memory formation. Tremendous researches have concluded that modulation of neural plasticity can assist the function restoration from brain lesion and spinal cord injury and may facilitate the recovery of patients suffering from stroke, depression, and Parkinson disease. Neural plasticity modulation may be influenced by many factors including age, pharmacology, motor training, sensory input, non-invasive brain stimulation and gene expression. In this article, these factors are discussed separately in following sections.

\section{Age}

Neural plasticity may reduce with advancing age. Rogasch et al. [4] examined changes in corticomotor excitability and plasticity after a thumb abduction training task in 14 young (18-24 yr) and 14 old (61-82 yr) adults. The training task consisted of 300 ballistic abductions of the right thumb to maximize peak thumb abduction acceleration (TAAcc). TMS of the left primary motor cortex was used to access changes in abductor pollicis brevis (APB) and abductor digiti minimi (ADM) muscles motor evoked potentials (MEPs) and short-interval intracortical inhibition (SCSI). After motor training, $77 \%$ and $24 \%$ improvement in peak TAAcc were observed in young and old group respectively. Meanwhile, the APB MEP amplitude increased 50\% in young subjects, while no changes were found in old subjects. These experiment results suggest that neural plasticity diminishes in older adults. Todd et al. [5] also examined the age effect to neural plasticity by applying inhibitory repetitive transcranial magnetic stimulation to young $(25 \pm 4 \mathrm{yr})$ and old $(67 \pm 5 \mathrm{yr})$ groups. Their experiment results indicate that the MEP amplitude recorded from first dorsal interoseus (FDI) muscle after 10 minutes of rTMS reduced 15\% in the young group, with no changes in old group. It is supportive to the hypothesis that age is accompanied by reduced neural plasticity. Possible causes of the neural plasticity decreasing in older people may include the reduction in the number of synapses [6], the size of compound excitatory postsynaptic potentials [7], the number of cells (Henderson, Tomlinson et al. 1980), the volume of gray matter [8] and atrophy of spinal motoneurones [9]. Several researches have confirmed that advancing age is associated with neural plasticity diminishing. However, Cirillo et al. [10] recently published a paper arguing that although an agerelated decline in motor learning occurred for the dominant hand, use-dependent corticomotor plasticity was not altered with advancing age in a simple thumb-training task. The mechanism of this age-related maintenance in neural plasticity remains to be determined.

\section{Pharmacological modulation}

Pharmacological modulation has been utilized to improve recovery of motor function. As early as in 1981, Feeney et al. [11] reported that a single dose of d-amphetamine (AMPH) given the day following a unilateral sensorimotor cortex ablation resulted in improved motor recovery in rats. This initial study introduced the positive effect of $\mathrm{d}$-amphetamine to the recovery of motor function and triggered tremendous further researches on humans [12-15]. Butefisch et al. [16] investigated six subjects' performance of a simple motor task under

*Corresponding author: Maxwell Boakye, Associate Professor of Neurosurgery, Ole A., Mabel Wise \& Wilma Wise Nelson Endowed Chair Director of Spinal Neurosurgery, Department of Neurosurgery, University of Louisville, Louisville, Kentucky, United States, E-mail: greatmaxx@gmail.com

Received October 09, 2011; Accepted November 01, 2011; Published November 18, 2011

Citation: Li K, Boakye M (2011) Neural Plasticity: Influencing Elements and Modulation Techniques. J Neurol Neurophysiol S4. doi:10.4172/2155-9562.S4-003

Copyright: @ $2011 \mathrm{Li} \mathrm{K}$, et al. This is an open-access article distributed under the terms of the Creative Commons Attribution License, which permits unrestricted use, distribution, and reproduction in any medium, provided the original author and source are credited. 
the effects of placebo and AMPH in a randomized, double-blind, counterbalanced experiment. The results suggest that AMPH induces increased magnitude, faster development and longer lasting duration of use-dependent plasticity and confirm the hypothesis that AMPH has facilitatory effect on neural plasticity. The mechanisms underlying the effect of AMPH are not completely understood, but they may include AMPH induced presynaptic release of the monoamines norepinephrine, dopamine and serotonin, inhibition of their reuptake [17-20], and enhancement of alpha adrenergic neurotransmission secondary to amphetamine-dependent release of norepinephrine [21]. It is also reported by Sawaki et al. that drugs that antagonize the effects of norepinephrine, such as prazosin, decreased the effectiveness of motor training in eliciting use-dependent plasticity measured by TMS [22]. Although AMPH may bring transient side effect including irritability, increased alertness, and a feeling of being detached from the environment [16], it is conceivable that d-amphetamine enhances the neural plasticity thought to contribute to functional recovery after brain injury and cortical lesions [11,23].

\section{Motor training}

Motor training has been proved capable of modulating neural plasticity [2,24]. Although the within-session effect of motor training is still controversial [25-27], consistency has been reported in the slowly developing increase of activation [27-29]. The plasticity modulation effect of motor training may also depend on the complexity of the motor task presented to the subjects. While many studies have confirmed that elementary motor training can change neural plasticity [30-32], researches also provided evidences that skilled motor training is more beneficial to the neural plasticity modulation $[33,34]$. Smyth et al. [35] analyzed the performance outcome of a wrist flexion-extension waveform-tracking task in two groups of 10 subjects, with one group was given $100 \%$ feedback (FB) and the other group was given only $50 \%$ FB during the task [35]. Interestingly, although no cortical excitability changes were observed during the acquisition, the 50\% FB group had elevated primary motor cortex excitability at retention (24 hrs after motor training). This effect may due to the increased cognitive complexity in the 50\% FB group, which additionally modulated the learning associated plasticity [36,37]. Motor training induced motor cortex excitability may reduce in skilled subjects compared to nonskilled subjects when performing the same motor task [38-40]. This effect has been explained as diminished neural effort is required for a particular motor task with a history of intense motor training [32].

\section{Sensory input modulation}

It has been reported that manipulation of sensory input has the ability to modulate the excitability of the primary motor cortex in animal model [41,42]. Further studies on human cortex demonstrated that rapid motor representation may incurred by disruption of sensory input, such as amputation, ischemic nerve block, or blood pressure cuff $[24,43]$. Kaelin-Lang, et al. [44] analyzed the MEPs recorded from abductor pollicis brevis (APB), first dorsal interosseous (FDI) and abductor digiti minimi (ADM) muscles after a 2-hour period of ulnar nerve electrical stimulation at the wrist and concluded that somatosensory stimulation elicited a focal increase on corticomotoneuronal excitability that outlasts the stimulation period and probably occurs at cortical sites. Khaslavskaia et al. [45] also reported increased motor cortex excitability after electrical stimulation measured by TMS in tibialis anterior (TA) muscle.

\section{Non-invasive brain stimulation}

Non-invasive brain stimulation techniques have been developed rapidly in the past two decades as a useful and promising tool for neuroscientists. Transcranial direct current stimulation (tDCS) and repetitive transcranial magnetic stimulation (rTMS), two techniques that can purposefully enhance or decrease excitability in focal areas of the brain, allow researchers to explore the facilitate activity in specific cortical areas in motor learning in an attempt to improve motor function [46].

Single pulse transcranial magnetic stimulation (TMS) elicited MEPs have been widely used as effective measurement of neural plasticity. It operates by creating a pulse magnetic field, which induces focal current flow that activates the targeted cortical brain area [47]. TMS under the frequency of $0.1 \mathrm{~Hz}$ are considered unable to induce neural plasticity. However rTMS protocols including theta-burst stimulation (TBS) [48] have been proved as safe and noninvasive techniques that have the ability of neural plasticity modulation $[49,50]$. Generally, low-frequency rTMS (i.e. $1 \mathrm{~Hz}$ ) induces inhibitory effects on motor cortical excitability [51] while high-frequency rTMS $(5-20 \mathrm{~Hz})$ usually increase cortical excitability [52,53]. It is believed that rTMS is able to interfere with the motor learning, skill acquisition, memory consolidation and reconsolidation process through stimulation on the primary motor cortex [54-62] and non-primary motor cortices [6368]. Different motor tasks may be more dependent on motor cortex or non-motor cortical areas like premotor cortex, posterior-parietal area and basal ganglia $[69,70]$. Therefore, TMS effects on behavior cannot be automatically conjectured from its effects on motor cortical excitability [71]. rTMS is also utilized as a useful tool in studies of interaction between hemispheres [72-74] and believed to be able to enhance the treatment effect in depression patients [75-78].

tDCS is another non-invasive procedure of cortical stimulation which uses weak direct current to polarize target brain area. Depending on the polarity of the stimulation, tDCS can be divided as anodal tDCS and cathodal tDCS that increase and decrease cortical excitability in the stimulated brain regions respectively [79]. tDCS has the ability to modulate neural plasticity and thereby enables the investigation of the causal relationships between brain activity. With several advantages over TMS, such as producing less artifact, low cost and great potential for cognitive and motor enhancement without seizure reported, tDCS is considered not only a complementary tool to TMS, but also a unique technique in current neuroscience [80].

\section{Gene expression}

A recent popping up question in neural plasticity studies is whether plasticity in human motor cortex is in part genetically determined? According to de Geus et al.'s review [81], there are about 100 genes currently considered have influence to human brain function and cognition, in which brain-derived neurotrophic factor gene (BNDF) is believed to be the most promising way to better understand the multifaceted role of BDNF variants in different plasticity protocols $[82,83]$. BDNF, as a key neural signal that orchestrate synaptic plasticity [84], is elevated within motor cortex in response to motor training [85]. Kleim et al. [86] studied the relationship between cortical plasticity and BNDF with a val66met polymorphism by investigating the MEP amplitude recruitment curve (RC), cortical representational area, normalized map volume and center of gravity (COG) in $9 \mathrm{Val} / \mathrm{Val}, 11$ 
$\mathrm{Val} / \mathrm{Met}$ and $6 \mathrm{Met} / \mathrm{Met}$ subjects [86]. Their experiment results indicate that although no baseline differences were observed in corticospinal output or motor map area between Val and Met subjects, a brief period of motor training enhanced corticospinal output and increased motor map area in Val/Val, but not Val/Met or Met/Met subjects [86]. This outcome is consistent with former researches $[87,88]$ and supports the hypothesis that BDNF is involved in mediating use-dependent plasticity of human motor cortex. Cheeran et al. [89] studied human cortical plasticity in subjects with BDNF polymorphism by using different protocols [89]. The significant differences of cortical plasticity changes in $\mathrm{Val} / \mathrm{Val}$ subjects and Met allele carriers drove them to hypothesize that BDNF polymorphism and the number of alleles may be associated with cortical plasticity modulation. Missitzi et al. [82] furthered Cheeran et al. [89] research by studying paired associative stimulation (PAS) induced neural plasticity in monozygotic (MZ) and dizygotic (DZ) twins [82]. It was found that the intrapair differences in MEP amplitudes measured 25-30 minutes post-intervention at APB muscle were almost double for $\mathrm{DZ}$ in comparison to $\mathrm{MZ}$ twins. This result more convincingly supports the hypothesis that interindividual variability in excitability changes of the motor cortex may due to the BDNF polymorphism and implicates that genetic factors may contribute significantly to the interindividual variation of neural plasticity.

\section{Summary}

Neural plasticity, as the reorganization ability of human or animal's neural system adapting to the environment input, has been studied for more than three decades. In this review, we discussed the factors that may affect neural plasticity and the available modulation techniques that can be utilized to induce neural plasticity. With abundant evidences, age, medicine (d-amphetamine), and gene expression have been proved as important factors that may affect neural plasticity. Motor training and modulation techniques, such as sensory input, rTMS and tDCS, have been widely used to induce neural plasticity in humans. Despite of the great progresses that have been achieved in neural plasticity studies, there are still many blank areas need further explorations. For example, the mechanisms of the maintenance of neural plasticity in older subjects, the medicine assisted neural plasticity modulation, the design of skilled motor task that enhances neural plasticity modulation and the relationship between gene expression and variation of neural plasticity. Future researches should also include the clinic use of the neural plasticity modulation techniques and the development of more effective modulation protocols by combining the available techniques, while stay alert to the influencing factors.

\section{References}

1. Nudo RJ, Plautz EJ, Frost SB (2001) Role of adaptive plasticity in recovery of function after damage to motor cortex. Muscle Nerve 24: 1000-1019.

2. Classen J, Liepert J, Wise SP, Hallett M, Cohen LG (1998) Rapid plasticity of human cortical movement representation induced by practice. $J$ neurophysiol 79: $1117-1123$

3. Muellbacher W, Ziemann U, Boroojerdi B, Cohen L, Hallett M (2001) Role of the human motor cortex in rapid motor learning. Exp Brain Res 136: 431-438.

4. Rogasch NC, Dartnall TJ, Cirillo J, Nordstrom MA, Semmler JG (2009) Corticomotor plasticity and learning of a ballistic thumb training task are diminished in older adults. J Appl Physiol 107: 1874-1883.

5. Todd G, Kimber TE, Ridding MC, Semmler JG (2010) Reduced motor cortex plasticity following inhibitory rTMS in older adults. Clin Neurophysiol 121: 441447
6. Adams I (1987) Comparison of synaptic changes in the precentral and postcentral cerebral cortex of aging humans: a quantitative ultrastructural study. Neurobiol Aging 8: 203-212.

7. Eisen A, Entezari-Taher M, Stewart H (1996) Cortical projections to spinal motoneurons: changes with aging and amyotrophic lateral sclerosis. Neurology 46: $1396-1404$.

8. Good CD, Johnsrude IS, Ashburner J, Henson RN, Friston KJ, et al. (2001) A voxel-based morphometric study of ageing in 465 normal adult human brains. Neuroimage 14: 21-36.

9. Doherty TJ, Vandervoort AA, Brown WF (1993) Effects of ageing on the motor unit: a brief review. Can J Appl Physiol 18: 331-358.

10. Cirillo J, Rogasch NC, Semmler JG (2010) Hemispheric differences in usedependent corticomotor plasticity in young and old adults. Exp Brain Res 205 57-68.

11. Feeney DM, Gonzales A, Law WA (1981) Amphetamine restores locomotor function after motor cortex injury in the rat. Proc West Pharmacol Soc 24: 1517.

12. Crisostomo EA, Duncan PW, Propst M, Dawson DV, Davis JN (1988) Evidence that amphetamine with physical therapy promotes recovery of motor function in stroke patients. Ann Neurol 23: 94-97.

13. Walker-Batson D, Unwin H, Curtis S, Allen E, Wood M, et al. (1992) Use of amphetamine in the treatment of aphasia. Restor Neurol Neurosci 4: 47-50.

14. Walker-Batson D, Smith P, Curtis S, Unwin H, Greenlee R (1995) Amphetamine paired with physical therapy accelerates motor recovery after stroke. Further evidence. Stroke 26: 2254-2259.

15. Walker-Batson D, Curtis S, Natarajan R, Ford J, Dronkers N, et al. (2001) A double-blind, placebo-controlled study of the use of amphetamine in the treatment of aphasia. Stroke; 32: 2093-2098.

16. Butefisch CM, Davis BC, Sawaki L, Waldvogel D, Classen J, et al. (2002) Modulation of use-dependent plasticity by d-amphetamine. Annals neurol 51 : 59-68.

17. Creese I, Iversen SD (1975) The pharmacological and anatomical substrates of the amphetamine response in the rat. Brain res 83: 419-436.

18. Boyeson MG, Feeney DM (1990) Intraventricular norepinephrine facilitates motor recovery following sensorimotor cortex injury. Pharmacol Biochem Behav 35: 497-501.

19. Goldstein LB (1993) Basic and clinical studies of pharmacologic effects on recovery from brain injury. J Neural Transplant Plast 4: 175-192.

20. Boyeson MG, Jones JL (1994) Sparing of motor function after cortical injury. A new perspective on underlying mechanisms. Arch Neurol 51: 405-414.

21. Feeney DM, Westerberg VS (1990) Norepinephrine and brain damage: alpha noradrenergic pharmacology alters functional recovery after cortical trauma Can J Psychol 44: 233-252.

22. Sawaki L, Werhahn KJ, Barco R, Kopylev L, Cohen LG (2003) Effect of an alpha(1)-adrenergic blocker on plasticity elicited by motor training. Exp Brain Res 148: 504-508.

23. Butefisch C, Hummelsheim H, Denzler P, Mauritz KH (1995) Repetitive training of isolated movements improves the outcome of motor rehabilitation of the centrally paretic hand. J Neurol Sci 130: 59-68.

24. Cohen LG, Brasil-Neto JP, Pascual-Leone A, Hallett M (1993) Plasticity of cortical motor output organization following deafferentation, cerebral lesions, and skill acquisition. Adv Neurol 63: 187-200.

25. Karni A, Meyer G, Jezzard P, Adams MM, Turner R, et al. (1995) Functional MRI evidence for adult motor cortex plasticity during motor skill learning. Nature 377: 155-158.

26. lacoboni M, Woods RP, Mazziotta JC (1996) Brain-behavior relationships: evidence from practice effects in spatial stimulus-response compatibility. J Neurophysiol 76: 321-331.

27. Karni A, Meyer G, Rey-Hipolito C, Jezzard P, Adams MM, et al. (1998) The 
acquisition of skilled motor performance: fast and slow experience-driven changes in primary motor cortex. Proc Natl Acad Sci U S A 95: 861-868.

28. Ungerleider LG, Doyon J, Karni A (2002) Imaging brain plasticity during motor skill learning. Neurobiol Learn Mem 78: 553-564

29. Hlustik P, Solodkin A, Noll DC, Small SL (2004) Cortical plasticity during threeweek motor skill learning. J Clin Neurophysiol 21: 180-191.

30. Carey LM, Abbott DF, Egan GF, Tochon-Danguy HJ, Donnan GA (2000) The functional neuroanatomy and long-term reproducibility of brain activation associated with a simple finger tapping task in older healthy volunteers: a serial PET study. Neuroimage 11: 124-144.

31. Tracy JI, Faro SS, Mohammed F, Pinus A, Christensen H, et al. (2001) A comparison of 'Early' and 'Late' stage brain activation during brief practice of a simple motor task. Brain research. Cognitive brain research 10: 303-316.

32. Koeneke S, Lutz K, Herwig U, Ziemann U, Jäncke L (2006) Extensive training of elementary finger tapping movements changes the pattern of motor cortex excitability. Exp Brain Res 174: 199-209.

33. Pascual-Leone A, Nguyet D, Cohen LG, Brasil-Neto JP, Cammarota A, et al. (1995) Modulation of muscle responses evoked by transcranial magnetic stimulation during the acquisition of new fine motor skills. J Neurophysiol 74 1037-1045.

34. Perez MA, Lungholt BK, Nyborg K, Nielsen JB (2004) Motor skill training induces changes in the excitability of the leg cortical area in healthy humans. Exp Brain Res 159: 197-205.

35. Smyth C, Summers JJ, Garry MI (2010) Differences in motor learning success are associated with differences in M1 excitability. Hum Mov Sci 29: 618-630.

36. Stefan K, Wycislo M, Classen J (2004) Modulation of associative human motor cortical plasticity by attention. J Neurophysiol 92: 66-72.

37. Thomson RH, Garry MI, Summers JJ (2008) Attentional influences on shortinterval intracortical inhibition. Clin Neurophysiol 119: 52-62.

38. Lotze M, Scheler G, Tan H-RM, Braun C, Birbaumer N (2003) The musician's brain: functional imaging of amateurs and professionals during performance and imagery. Neurolmage 20: 1817-1829.

39. Haslinger B, Erhard P, Altenmüller E, Hennenlotter A, Schwaiger M, et al (2004) Reduced recruitment of motor association areas during bimanual coordination in concert pianists. Hum Brain map 22: 206-215.

40. Koeneke S, Lutz K, Wüstenberg T, Jäncke L (2004) Long-term training affects cerebellar processing in skilled keyboard players. Neuroreport 15: 1279-1282.

41. Asanuma H, Rosen I (1972) Functional role of afferent inputs to the monkey motor cortex. Brain Res 40: 3-5.

42. Asanuma $\mathrm{H}$, Arissian K (1984) Experiments on functional role of peripheral input to motor cortex during voluntary movements in the monkey. J Neurophysiol 52 212-227.

43. Ziemann U, Corwell B, Cohen LG (1998) Modulation of plasticity in human motor cortex after forearm ischemic nerve block. J Neurosci 18: 1115-1123.

44. Kaelin-Lang A, Luft AR, Sawaki L, Burstein AH, Sohn YH, et al. (2002) Modulation of human corticomotor excitability by somatosensory input. J physiol 540: 623-633.

45. Khaslavskaia S, Ladouceur M, Sinkjaer T (2002) Increase in tibialis anterior motor cortex excitability following repetitive electrical stimulation of the common peroneal nerve. Exp Brain Res 145: 309-315.

46. Reis J, Robertson E, Krakauer JW, Rothwell J, Marshall L, et al. (2008) Consensus: Can tDCS and TMS enhance motor learning and memory formation?. Brain Stimul 1: 363-369.

47. Hallett M (2007) Transcranial magnetic stimulation: a primer. Neuron 55: 187 199.

48. Huang YZ, Edwards MJ, Rounis E, Bhatia KP, Rothwell JC (2005) Theta burst stimulation of the human motor cortex. Neuron 45: 201-206.

49. Wassermann EM (1998) Risk and safety of repetitive transcranial magnetic stimulation: report and suggested guidelines from the International Workshop on the Safety of Repetitive Transcranial Magnetic Stimulation, June 5-7, 1996. Electroencephalogr Clin Neurophysiol 108: 1-16.

50. Rossi S, Hallett M, Rossini PM, Pascual-Leone A, Safety of TMS Consensus Group (2009) Safety, ethical considerations, and application guidelines for the use of transcranial magnetic stimulation in clinical practice and research. Clin Neurophysiol 120: 2008-2039.

51. Chen R, Classen J, Gerloff C, Celnik P, Wassermann EM, et al. (1997) Depression of motor cortex excitability by low-frequency transcranial magnetic stimulation. Neurology 48: 1398-1403.

52. Pascual-Leone A, Valls-Solé J, Wassermann EM, Hallett M (1994) Responses to rapid-rate transcranial magnetic stimulation of the human motor cortex. Brain 117: 847-858.

53. Berardelli A, Inghilleri M, Rothwell JC, Romeo S, Currà A, et al. (1998) Facilitation of muscle evoked responses after repetitive cortical stimulation in man. Exp Brain Res 122: 79-84.

54. Brashers-Krug T, Shadmehr R, Bizzi E (1996) Consolidation in human motor memory. Nature 382: 252-255.

55. Muellbacher W, Ziemann U, Wissel J, Dang N, Kofler M, et al. (2002) Early consolidation in human primary motor cortex. Nature 415: 640-644.

56. Walker MP, Brakefield T, Morgan A, Hobson JA, Stickgold R (2002) Practice with sleep makes perfect: sleep-dependent motor skill learning. Neuron 35 205-211.

57. Richardson AG, Overduin SA, Valero-Cabré A, Padoa-Schioppa C, PascualLeone A, et al. (2006) Disruption of primary motor cortex before learning impairs memory of movement dynamics. J Neurosci 26: 12466-12470.

58. Korman M, Doyon J, Doljansky J, Carrier J, Dagan Y, et al. (2007) Daytime sleep condenses the time course of motor memory consolidation. Nat Neurosci 10: $1206-1213$

59. Hotermans C, Peigneux P, de Noordhout AM, Moonen G, Maquet P (2008) Repetitive transcranial magnetic stimulation over the primary motor cortex disrupts early boost but not delayed gains in performance in motor sequence learning. Eur J Neurosci 28: 1216-1221.

60. Brown LE, Wilson ET, Gribble PL (2009) Repetitive transcranial magnetic stimulation to the primary motor cortex interferes with motor learning by observing. J Cogn Neurosci 21: 1013-1022.

61. Debas K, Carrier J, Orban P, Barakat M, Lungu O, et al. (2010) Brain plasticity related to the consolidation of motor sequence learning and motor adaptation. Proc Natl Acad Sci U S A 107: 17839-17844.

62. lezzi E, Suppa A, Conte A, Agostino R, Nardella A, et al. (2010) Theta-burs stimulation over primary motor cortex degrades early motor learning. Eur $J$ Neurosci 31: 585-592.

63. Del Olmo MF, Cheeran B, Koch G, Rothwell JC (2007) Role of the cerebellum in externally paced rhythmic finger movements. J Neurophysiol 98: 145-152.

64. Oliveri M, Torriero S, Koch G, Salerno S, Petrosini L, et al. (2007) The role of transcranial magnetic stimulation in the study of cerebellar cognitive function Cerebellum 6: 95-101.

65. Tseng YW, Diedrichsen J, Krakauer JW, Shadmehr R, Bastian AJ (2007) Sensory prediction errors drive cerebellum-dependent adaptation of reaching. J Neurophysiol 98: 54-62.

66. Perez MA, Tanaka S, Wise SP, Willingham DT, Cohen LG (2008) Timespecific contribution of the supplementary motor area to intermanual transfer of procedural knowledge. J Neurosci 28: 9664-9669.

67. Galea JM, Albert NB, Ditye T, Miall RC (2010) Disruption of the dorsolatera prefrontal cortex facilitates the consolidation of procedural skills. J Cogn Neurosci 22: 1158-1164.

68. Kantak SS, Sullivan KJ, Fisher BE, Knowlton BJ, Winstein CJ (2010) Neura substrates of motor memory consolidation depend on practice structure. Nat Neurosci 13: 923-925.

69. Catalan MJ, Honda M, Weeks RA, Cohen LG, Hallett M (1998) The functional neuroanatomy of simple and complex sequential finger movements: a PET study. Brain 121: 253-264. 
Citation: Li K, Boakye M (2011) Neural Plasticity: Influencing Elements and Modulation Techniques. J Neurol Neurophysiol S4. doi:10.4172/21559562.S4-003

70. Mima T, Sadato N, Yazawa S, Hanakawa T, Fukuyama H, et al. (1999) Brain structures related to active and passive finger movements in man. Brain 122: 1989-1997.

71. Sczesny-Kaiser M, Tegenthoff M, Schwenkreis $P$ (2009) Influence of $5 \mathrm{~Hz}$ repetitive transcranial magnetic stimulation on motor learning. Neurosci lett 457: 71-74.

72. Schambra HM, Sawaki L, Cohen LG (2003) Modulation of excitability of human motor cortex (M1) by $1 \mathrm{~Hz}$ transcranial magnetic stimulation of the contralateral M1. Clin Neurophysiol 114: 130-133.

73. Kobayashi M, Hutchinson S, Théoret H, Schlaug G, Pascual-Leone A (2004) Repetitive TMS of the motor cortex improves ipsilateral sequential simple finger movements. Neurology 62: 91-98.

74. Chiang TC, Vaithianathan T, Leung T, Lavidor M, Walsh V, et al. (2007) Elevated haemoglobin levels in the motor cortex following $1 \mathrm{~Hz}$ transcranial magnetic stimulation: a preliminary study. Experimental brain research. Exp Brain Res 181: 555-560.

75. Arns M, Spronk D, Fitzgerald PB (2010) Potential differential effects of $9 \mathrm{~Hz}$ rTMS and $10 \mathrm{~Hz}$ rTMS in the treatment of depression. Brain Stimul 3: 124-126.

76. Baeken C, De Raedt R, Santermans L, Zeeuws D, Vanderhasselt MA, et al. (2010) HF-rTMS treatment decreases psychomotor retardation in medicationresistant melancholic depression. Prog Neuropsychopharmacol Biol Psychiatry 34: 684-687.

77. Schonfeldt-Lecuona C, Lefaucheur JP, Cardenas-Morales L, Wolf RC Kammer T, et al. (2010) The value of neuronavigated rTMS for the treatment of depression. Neurophysiol Clin 40: 37-43.

78. Triggs WJ, Ricciuti N, Ward HE, Cheng J, Bowers D, et al. (2010) Right and left dorsolateral pre-frontal rTMS treatment of refractory depression: a randomized, sham-controlled trial. Psychiatry Res 178: 467-474.

79. Nitsche MA, Paulus W (2000) Excitability changes induced in the human moto cortex by weak transcranial direct current stimulation. J Physiol 527: 633-639.
80. Tanaka S, Watanabe K (2009) Transcranial direct current stimulation--a new tool for human cognitive neuroscience. Brain nerve 61: 53-64.

81. de Geus E, Goldberg T, Boomsma DI, Posthuma D (2008) Imaging the genetics of brain structure and function. Biol Psychol 79: 1-8.

82. Missitzi J, Gentner R, Geladas N, Politis P, Karandreas N, et al. (2011) Plasticity in human motor cortex is in part genetically determined. J Physio 589: 297-306.

83. Paulus W (2011) Transcranial stimulation techniques: which genetics is the best for which purpose? J Physiol 589: 1245.

84. Lu B (2003) BDNF and activity-dependent synaptic modulation. Learn Mem 10: $86-98$.

85. Klintsova AY, Dickson E, Yoshida R, Greenough WT (2004) Altered expression of BDNF and its high-affinity receptor TrkB in response to complex motor learning and moderate exercise. Brain Res 1028: 92-104.

86. Kleim JA, Chan S, Pringle E, Schallert K, Procaccio V, et al. (2006) BDNF val66met polymorphism is associated with modified experience-dependent plasticity in human motor cortex. Nat Neurosci 9: 735-737.

87. Ishibashi H, Hihara S, Takahashi M, Heike T, Yokota T, et al. (2002) Tool-use learning induces BDNF expression in a selective portion of monkey anterio parietal cortex. Brain Res Mol Brain Res 102: 110-112.

88. Nanobashvili A, Jakubs K, Kokaia M (2005) Chronic BDNF deficiency permanently modifies excitatory synapses in the piriform cortex. J Neurosc Res 81: 696-705.

89. Cheeran B, Talelli P, Mori F, Koch G, Suppa A, et al. (2008) A common polymorphism in the brain-derived neurotrophic factor gene (BDNF) modulates human cortical plasticity and the response to rTMS. J Physiol 586: 5717-5725.

90. Henderson G, Tomlinson BE, Gibson PH (1980) Cell counts in human cerebra cortex in normal adults throughout life using an image analysing computer. $J$ Neurol Sci 46: 113-136.
This article was originally published in a special issue, Neurorehabilitation \& Neural Repair handled by Editor(s). Dr. Hsinlin Thomas Cheng, University of Michigan, USA 